Article

\title{
Analysis of NMR Spectra of Submicro-Containers with Biocide DCOIT
}

\author{
Saule B. Aidarova ${ }^{1,2, *}$, Assem B. Issayeva ${ }^{1,2}$, Altynay A. Sharipova ${ }^{1, *}$, Dmitry O. Grigoriev ${ }^{3}$, \\ Reinhard Miller ${ }^{4}{ }^{(}$, Tulegen M. Seilkhanov ${ }^{5}$, Alpamys A. Babayev ${ }^{2}$ and Miras O. Issakhov ${ }^{2}$ \\ 1 Industrial Engineering Department, Satbayev University, 22 Satpayev Street, Almaty 050013, Kazakhstan; \\ isa-asem@mail.ru \\ 2 "One Belt-One Road" Institute, Kazakh-British Technical University, 59 Tole bi Street, \\ Almaty 050000, Kazakhstan; a_babayev@mail.ru (A.A.B.); mir001@gmail.com (M.O.I.) \\ 3 Fraunhofer Institute for Applied Polymer Research IAP, Geiselbergstrasse 69, \\ 14476 Potsdam/Golm, Germany; dmitry.grigoriev@iap.fraunhofer.de \\ 4 Physics Department, Technical University Darmstadt, Hochschulstraße 8, 64289 Darmstadt, Germany; \\ miller@fkp.tu-darmstadt.de \\ 5 Department of Engineering, Sh. Ualikhanov Kokshetau State University, Kokshetau 020000, Kazakhstan; \\ tseilkhanov@mail.ru \\ * Correspondence: ainano9999@gmail.com (S.B.A.); a_sharipova85@mail.ru (A.A.S.); \\ Tel./Fax: +7-7772247855 (S.B.A.)
}

Received: 9 September 2020; Accepted: 27 November 2020; Published: 9 December 2020

\begin{abstract}
Nowadays, the search for and development of new forms of materials with biocides is an actual problem of the modern science of nanosized materials due to the problem of microbiological contamination, which can be solved by using nanocontainers carrying biocides. Depending on the morphology of the nanocontainers and the filled active agents, it is possible to create coatings with specially designed self-healing functionality or multifunctional properties. The purpose of this work was to produce submicro-containers (SMCs) with a shell of $\mathrm{SiO}_{2}$ nanoparticles and a core of polymerized 3-(trimethoxysilyl) propyl methacrylate filled with 5-dichloro-2-n-octyl-4-isothiazolin-3-one (DCOIT) in an oil in water $(\mathrm{O} / \mathrm{W})$ emulsion. The chemical nature of the individual components of the system and nano-capsules were investigated using NMR spectroscopy. The size and zeta potential of the SMCs were measured by a dynamic light scattering method $(\mathrm{d}=170-180 \mathrm{~nm}$, polydispersity index PDI $=0.125$ and zeta-potential $=55 \mathrm{mV})$, the morphology of their outer surface was determined using SEM. The results of NMR analysis showed that during the addition of the biocide into the SMCs, its chemical structure is retained, as is its activity. Minor changes in the chemical shifts of the ${ }^{1} \mathrm{H}$ NMR spectra of the SMCs with DCOIT, as well as of the biocide itself, confirm the inclusion of DCOIT inside the SMCs.
\end{abstract}

Keywords: nano-containers; NMR; encapsulation; biocide

\section{Introduction}

One of the urgent tasks of modern scientific and applied colloid chemistry and nanotechnology is the development of promising effective technologies for the encapsulation of active reagents, which are widely used in various industries [1-8]. In this respect, composite materials that can effectively modify practically important properties of dispersed systems are promising for the development of nanotechnologies and the production of new nanomaterials.

Currently, there is an intensive growth of research on the formation of micro-and nano-containers with unique properties and high potential for the development of effective medicines, pharmaceuticals, and paint materials. 
The development of materials with the ability to restore its main function is currently one of the fastest growing areas in materials science. In particular, protective coatings with the characteristics of an autonomous healing or restoration of their protective function are of great interest in the study of surface destruction processes, such as corrosion, biological fouling, and other factors affecting metal structures. It is possible to obtain such materials by microencapsulation of protective active agents via their incorporation into protective coatings [2-6].

Depending on the morphology of the containers and the filled active agents, coatings with specially designed self-healing functionality or multifunctional coatings can be created. In [9], for example, the possibility and conditions for the formation of nano- or submicro-capsules loaded with hydrophobic active ingredients (alkoxysilanes) into the matrix of coatings with a self-lubricating effect are considered.

Advanced methods for the study of microorganisms are used, which should be of great help in efforts to develop more effective antimicrobials to solve specific problems. The study of biocides with minimal negative environmental impact led to the creation of "green" biocides, a striking representative of which is 4,5-dichloro-2-n-octyl-4-isotriazolin-3-one (DCOIT). The main advantages of this biocide are that it has the widest spectrum of antimicrobial activity at already very low concentrations [10-12], it shows a self-regulation of concentration in aqueous media due to its poor water solubility [10-13].

To obtain highly effective submicro-dispersed materials with an antimicrobial active agent it is important and promising to develop and test polymer coatings containing submicro-containers (SMCs) loaded with a biocide. To develop SMCs with an antimicrobial agent systematic studies of the physicochemical properties of both constituent components and emulsions, their colloidal chemical properties in bulk and at various interfaces were investigated.

Another stage of research is the determination of biocide content in SMCs by NMR spectroscopy. DCOIT is an antifoulant widely used in marine biofouling as an alternative biocide for TBT (tributyltin), the use of which is forbidden due to its toxic effects on the marine environment. DCOIT showed better environmental behavior [14], as compared with TBT. DCOIT is a chlorinated isothiazolone used as a broad-spectrum booster biocide in antifouling paints, where it affects both soft- and hard-fouling. It is easily biodegraded with a reported half-life in natural seawater between $24 \mathrm{~h}$ and 3 days [11].

DCOIT is approved in the EU as an active substance in biocidal products of type 21-antifouling agents (No 437/2014 of 29 April 2014) [15]. It diffuses easily through cell membranes and cell walls [16], and causes oxidative stress in the cell followed by necrosis [17]. The mechanism of its toxic action seems to consist of the formation of free radicals [18] and in blocking the oxidative stress defense system. DCOIT inhibits glutathione reductase by irreversible binding to active centers of enzymes, and thereby, decreases the amount of cellular glutathione [16,17].

The authors of [18] address biologically influenced corrosion by electrodepositing 4,5-dichloro2-n-octyl-4 isothiazolin-3-one(DCOIT)-zinc composite films for enhanced corrosion resistance. Investigated by electrochemical methods, energy dispersive spectroscopy distribution mapping, and infrared absorption spectroscopy, a deposition mechanism was proposed, wherein the DCOIT molecules chelated the zinc ion participate in electrodeposition. The DCOIT-zinc chelate produced obvious alterations in the surface morphology and crystal orientations.

In our previous work [19] the encapsulation of DCOIT into containers with a polyurea shell was developed. The obtained micro- and nano-containers were characterized from their morphology and colloid-chemical properties and can be used for inclusion into new functional materials and coatings, providing them with long-term activity against a wide range of microorganisms. The studies revealed a monodispersity and positive charge of the containers, which have a folded morphology [19].

The adsorption ability of humic acids in the presence of different biocides like cyproconasol, propiconasol, tebuconasol, irgarol 1051, and DCOIT and the chemical composition of humic acids from brown coal (Aldrich) were studied by element analysis, ${ }^{13} \mathrm{C}$ NMR spectroscopy, and potentiometric titration [20]. The adsorption ability of the mixtures was higher than that of the individual components. The limiting concentrations of humic acids at which the adsorption of the biocides was maximum were determined. 
Nuclear magnetic resonance spectroscopy is widely used as an analytical and quantitative method for studying the structure of substances. It is an analysis method that uses the magnetic properties of some atomic nuclei that can absorb radio frequency energy when placed in a magnetic field, a characteristic force to identity the nuclei.

NMR spectroscopy of solutions has proved to be a powerful tool in the structural characterization of all types of chemical compounds [21]. NMR is also an invaluable tool for the qualitative and quantitative analyses of polymers, enabling the description of subtle molecular details. The chemical shift is the NMR parameter most often used for structure determination, although analysis of coupling patterns, relaxation behavior, or nuclear Overhauser enhancements can supply additional details. The multidimensional NMR approach allows complex chemical structures to be fully described by facilitating correlations of various spectral parameters [21].

Therefore, in this work, we studied the preparation of nanocapsules, the determination of the biocide content in SMCs and their characterization using scanning electron microscopy and NMR spectroscopy.

\section{Materials and Methods}

\subsection{Materials}

As the oil phase, 3-(trimethoxysilyl) propyl methacrylate (TPM) was used to prepare nanocapsules, obtained from AlfaAesar, 97\%, GmbH. Ludox AS-40 (Sigma-Aldrich Co., St. Louis, MO, USA). Hydrophilic non-aggregated amorphous silica nanoparticles obtained from Sigma-AldrichCo, Ludox AS-40, with the size $20-25 \mathrm{~nm}$ were used as the stabilizing agent for the preparation of the oil in water O/W emulsions. The oil-soluble biocide 4,5-Dichloro-2-n-octyl-4-isothiazolin-3-one (DCOIT) was introduced into the TPM. In the synthesis, Milli-Q water with a specific resistance of $18 \mathrm{M} \Omega \cdot \mathrm{cm}$ at $25^{\circ} \mathrm{C}$ was used. Other chemicals and solvents used are summarized in Table 1.

\subsection{Methods}

\subsubsection{Preparation of SMCs}

Details of the synthesis of SMCs has been presented previously in [22]. To obtain a Pickering emulsion, the initial $40 \%$ concentrated suspension of hydrophilic non-aggregated amorphous silica particles was diluted about 15 times in deionized water, i.e., $2.0 \mathrm{~g}$ of a suspension of silica was added to $40 \mathrm{~mL}$ of deionized water containing $128 \mathrm{mg}$ Irgacure 2959 as initiator (water solubility $7.6 \mathrm{~g} / \mathrm{L}$ at $\left.25^{\circ} \mathrm{C}\right)$ (2-hydroxy-4'-(2 hydroxyethoxy))-2-methylpropiophenone.

To prepare the oil phase in $1.6 \mathrm{~g}$ TPM, $0.16 \mathrm{~g}$ DCOIT and $128 \mathrm{mg}$ the initiator Irgacure 651 (2,2-dimethoxy-2-phenilacetophenone) were added. Then it was added to the prepared aqueous phase in a ratio of 1:19. Hand mixing was applied for a few seconds and the mixture was left in order for spontaneous emulsification to occur at room temperature for $24 \mathrm{~h}$. The Pickering emulsions were prepared with the addition of DCOIT biocide in the oil phase.

The following two steps were used to prepare the $\mathrm{O} / \mathrm{W}$ emulsions: hydrolysis and polycondensation. After TPM hydrolysis reaction with water, the formed silanols interact with silanol groups on the surface of the silica suspension particles and the latter become partially hydrophobic as a result of the polycondensation reaction occurring on their surface. Such particles contribute to the formation and subsequent stabilization of the Pickering $\mathrm{O} / \mathrm{W}$ emulsion, which forms spontaneously in the system.

I step: Hydrolysis:<smiles>C=C(C)C(=O)OCCC[Si](O)(O)O[Hg]CCO</smiles> 
II step: Polycondensation:<smiles>C=C(C)C(=O)OCCC[AsH](O)(O)O</smiles><smiles>C=C(C)C(=O)OCCC[Si](O)(O)O[Si](O)(O)CCCOC(=O)C(=C)C</smiles>

The emulsion was filtered, then the polymerization process was carried out under UV-Vis for $20 \mathrm{~min}$ by stirring with a magnetic stirrer at a speed of 350-400 rpm. The nanocontainers thus obtained were separated from the residues of the reaction mixture by centrifugation at $18,000 \mathrm{rpm}$ and washed with Milli-Q water 2 times with intermediate centrifugation under the same conditions. The finished SMCs were dried for $12 \mathrm{~h}$ at $35^{\circ} \mathrm{C}$.

The size and zeta-potential of SMCs were determined by dynamic light scattering, the details of which are presented elsewhere [22].

\subsubsection{NMR Spectroscopy}

All NMR measurements were performed at room temperature on a JNM-ECA Jeol 400 spectrometer operating at a frequency of $400 \mathrm{MHz}$ using chloroform as solvent. The chemical shifts are measured relative to the signals of residual protons or carbon atoms of deuterated chloroform.

\subsubsection{SEM Scanning Electron Microscopy}

The morphology of the outer surface of the SMCs was investigated by using a high-resolution scanning electron microscope (SEM, Control LEO 1550). The SMCs characterized in this study for SEM were prepared by drying droplets of diluted emulsions on special substrates.

\section{Results and Discussion}

In our previous work [22], the colloid chemical properties of subnano-containers loaded with a biocide were studied by dynamic light scattering using the Zeta Sizer Nano ZS (Malvern Instruments, Great Britain).

Suspensions of finished SMCs showed a very high degree of monodispersity. The average capsule size after polymerization was $146.1 \mathrm{~nm}$ and polydispersity PDI $=0.125$ (Figure 1).

Due to the fact that the shell of micro- and nano-capsules was formed by partially hydrophobic silica nanoparticles, the zeta potential of the obtained containers was determined by the electrokinetic properties of these particles, i.e., sub-microcontainers had a rather high negative charge at $\mathrm{pH}=7$. By measuring the zeta potentials, it was proven that after polymerization, the dispersed systems become more stable and less susceptible to aggregation and sedimentation, since the zeta potential of the emulsion droplets after polymerization increases to almost $-67.9 \mathrm{mV}$ (Figure 2). 


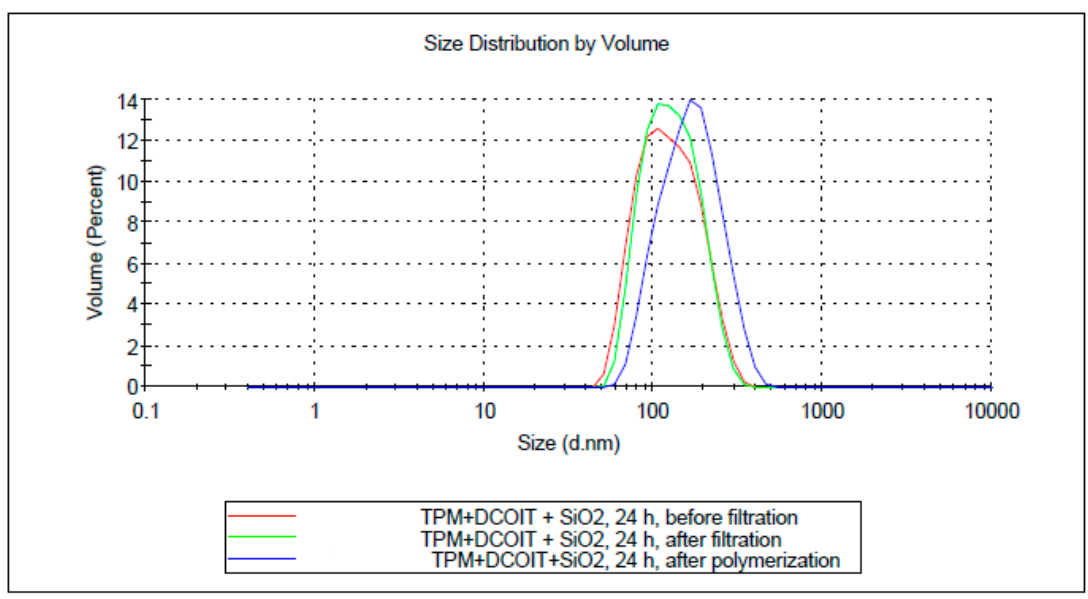

Figure 1. Size distribution curves of Pickering emulsion submicro-containers (SMCs) with a shell of silicon dioxide nanoparticles and a core of substituted polymerized 3-(trimethoxysilyl) propyl methacrylate (TPM) with 5-dichloro-2-n-octyl-4-isothiazolin-3-one (DCOIT) before and after polymerization [22].

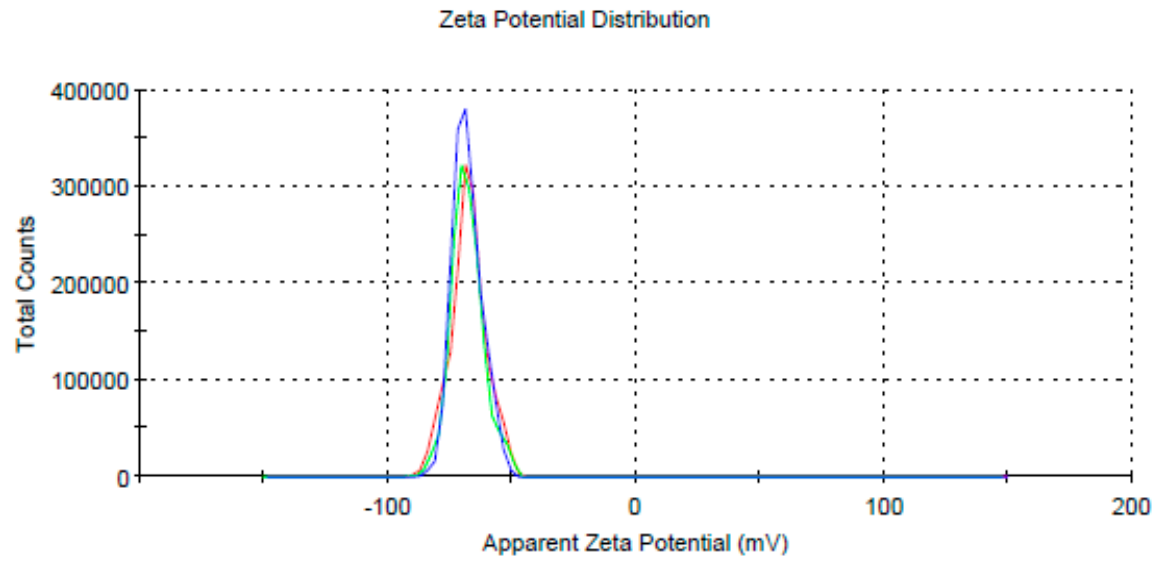

Figure 2. Zeta potential of SMCs [22] (three times repeated).

\subsection{Analysis of the NMR Spectra of the Sample DCOIT}

To control the polymerization process, as well as to control the preservation of the chemical structure of the biocide in the SMCs, ${ }^{1} \mathrm{H}$ and ${ }^{13} \mathrm{C}$ NMR analysis were performed.

The ${ }^{1} \mathrm{H}$ NMR spectrum of a compound is characterized by the presence of a triplet multiplet in the high-field part of the spectrum in the region of $0.83-0.86 \mathrm{ppm}$, with an integrated intensity of ${ }^{3} \mathrm{H}$ protons of the H-13,13,13 methyl fragment. Methylene protons $\mathrm{H}-8-12$ of the octyl fragment resonated with a ten-proton multiplet in the region of 1.23-1.28 ppm. Methylene protons H-7,7 and H-6,6 appeared with a quintet at $1.67\left(2 \mathrm{H},{ }^{3} \mathrm{~J} 6.8 \mathrm{~Hz}\right)$ and a triplet at $3.77\left(2 \mathrm{H},{ }^{3} \mathrm{~J} 7.8 \mathrm{~Hz}\right) \mathrm{ppm}$, respectively (Figure 3).

In the ${ }^{13} \mathrm{C}$ NMR spectrum of the compound, the signals of the octinyl substituent are observed at 14.18 (C-13), 22.69 (C-12), 26.47 (C-7), 29.14 (C-8, 10), 29.43 (C-9), 31.79 (C-11) and 45.23 (C-6) ppm. The carbon atoms of the five-membered heterocyclic ring resonated at 115.09 (C-4), 138.32 (C-5) and 161.92 (C-3) ppm. (Figure 4).

Figures 3 and 4 show the model $1 \mathrm{H}$ and 13C NMR spectra of the DCOIT sample obtained in the ACD Labs program. The $1 \mathrm{H}$ and 13C NMR spectra of DCOIT are shown in Figures 5 and 6, respectively. It should be noted that the order of the $1 \mathrm{H}$ and 13C NMR spectra of the DCOIT sample corresponds to the order of their arrangement in the model spectra. In the proton spectra of DCOIT, there is also a correlation between the number of corresponding protons in the molecule and the value of their integral intensity. 


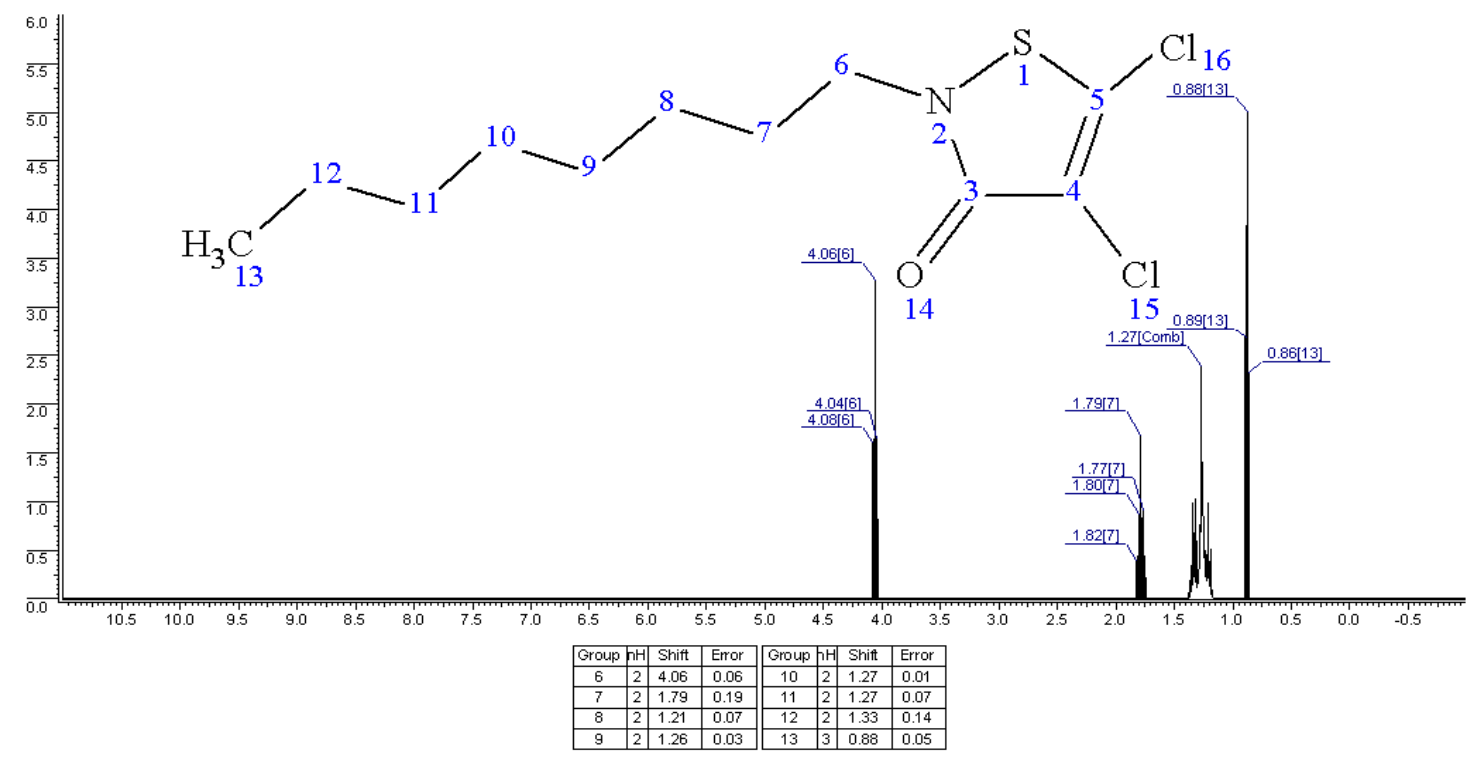

Figure $3 .{ }^{1} \mathrm{H}$ NMR spectra of DCOIT.

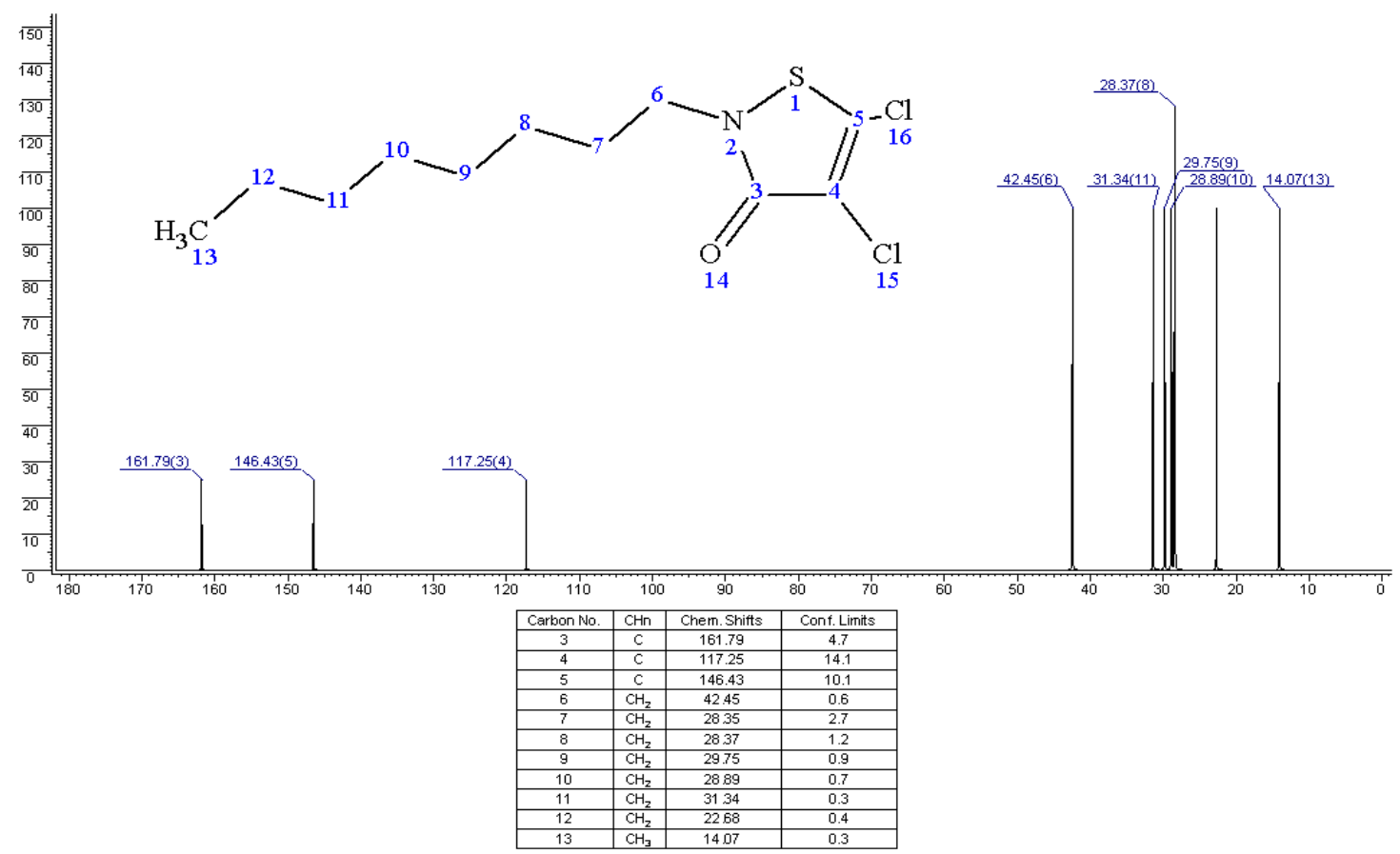

Figure $4 .{ }^{13} \mathrm{C}$ NMR spectra of DCOIT. 


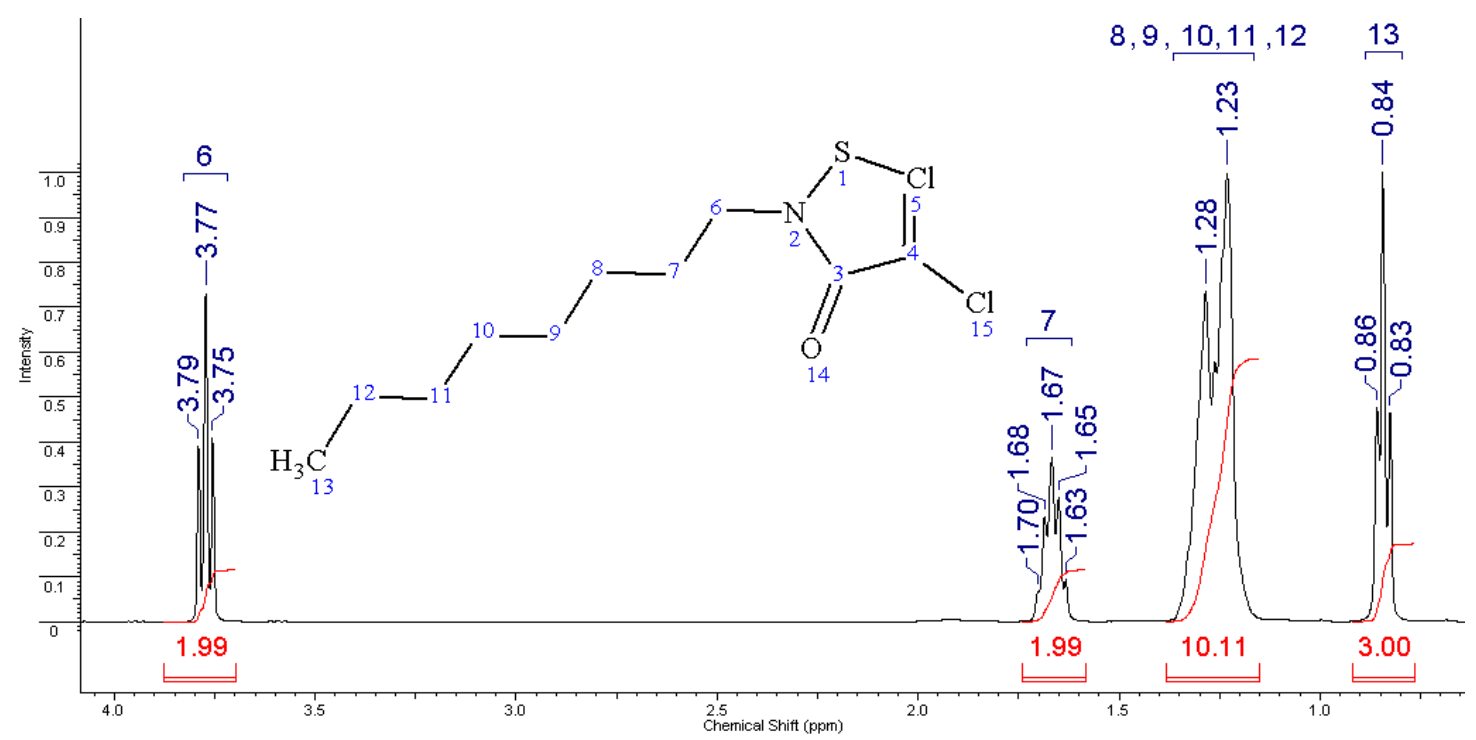

Figure 5. ${ }^{1} \mathrm{H}$ NMR spectra of DCOIT.

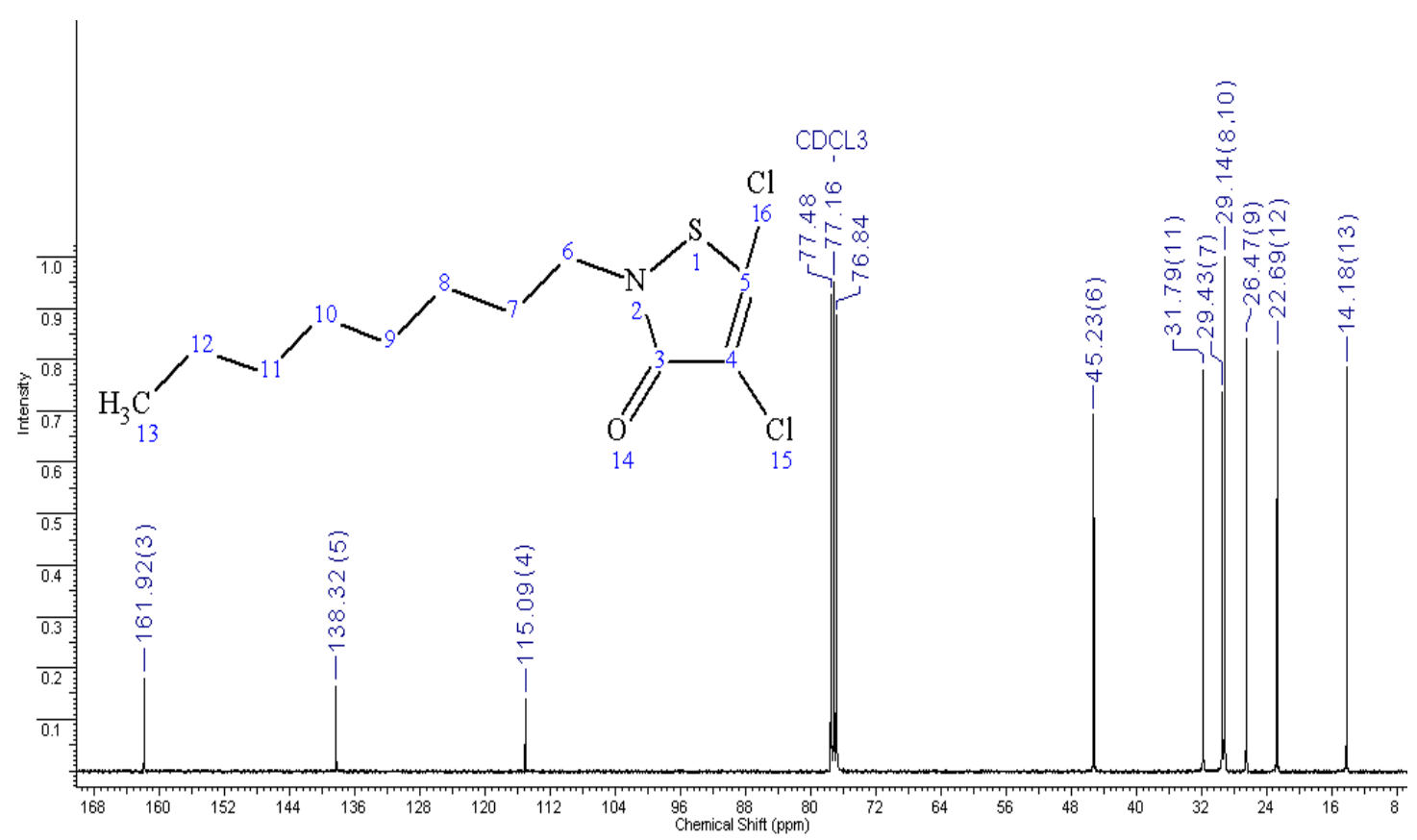

Figure 6. ${ }^{13} \mathrm{C}$ NMR spectra of DCOIT.

The structure of DCOIT was also confirmed by the methods of two-dimensional NMR spectroscopy COSY $\left({ }^{1} \mathrm{H}_{-}{ }^{1} \mathrm{H}\right)$ (Figure 7) and HMQC $\left({ }^{1} \mathrm{H}_{-}{ }^{13} \mathrm{C}\right)$ (Figure 8), which allows one to establish spin-spin interactions of a homonuclear nature. The observed correlations in the molecule are presented in the diagrams (Figure 9). 


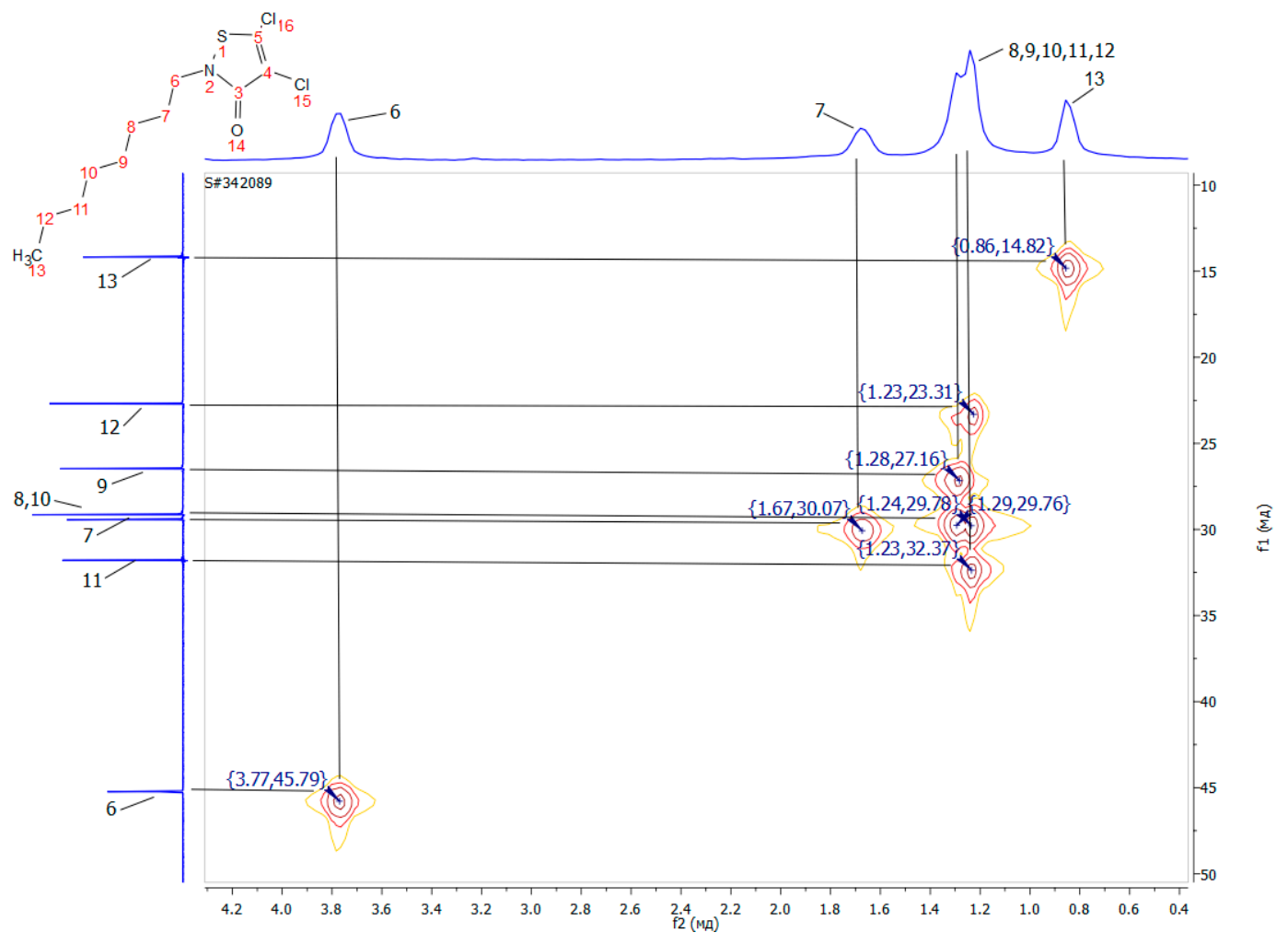

Figure 7. HMQC spectrum of a sample of DCOIT.

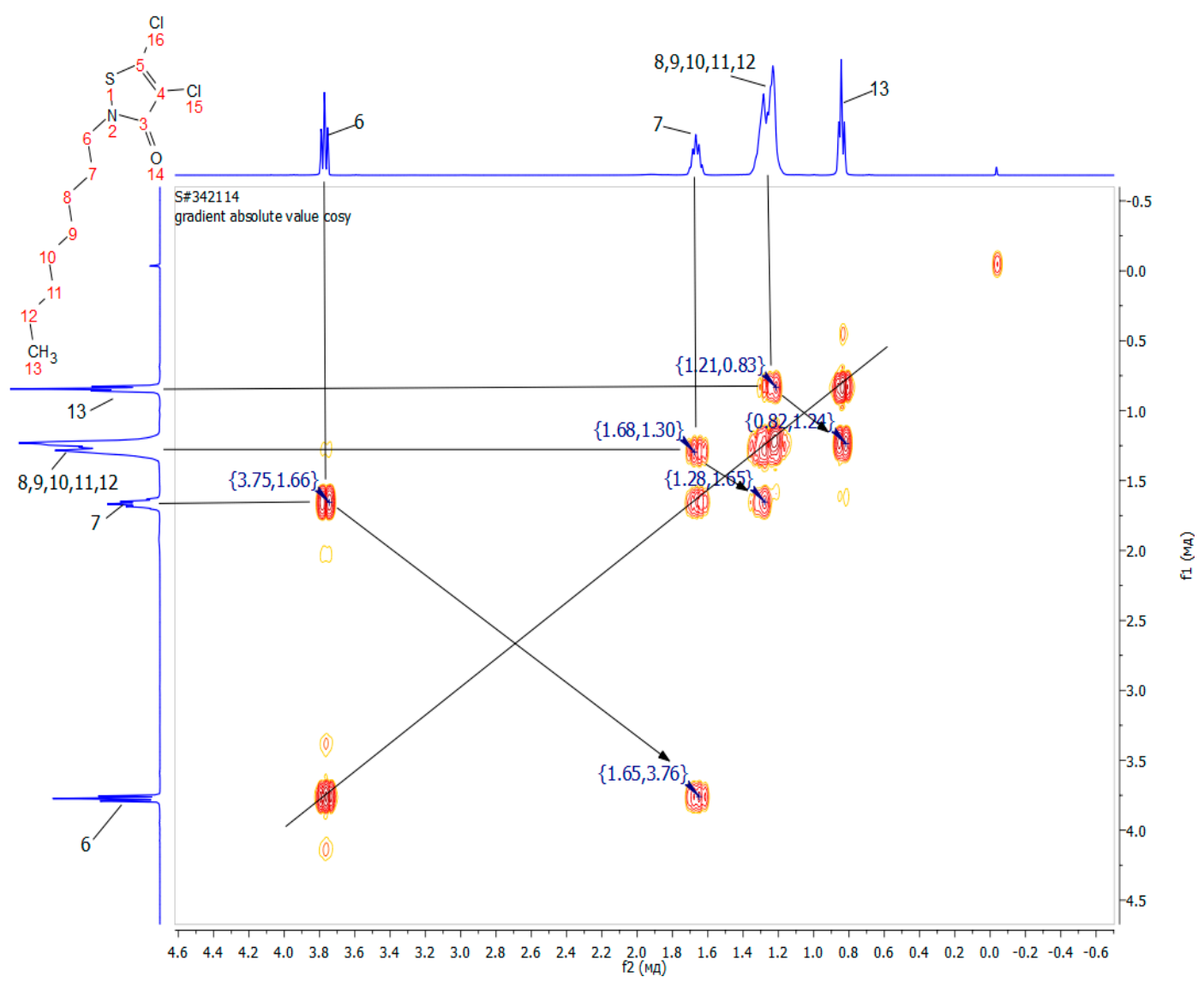

Figure 8. COSY spectrum of DCOIT. 


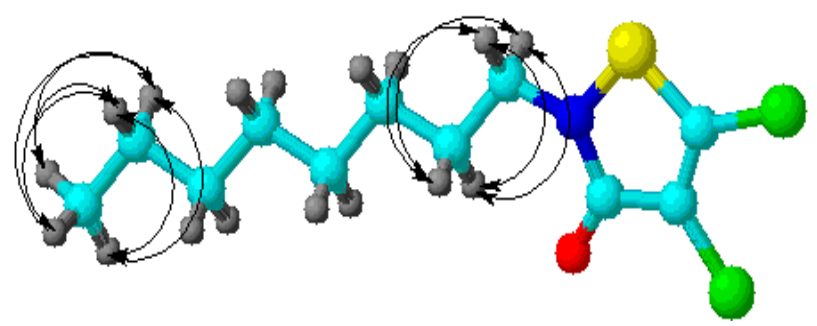

(a)

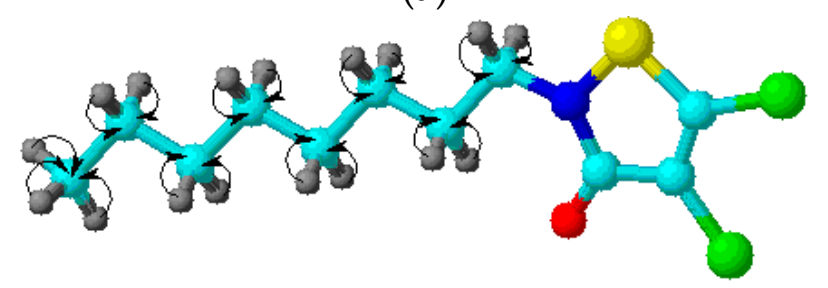

(b)

Figure 9. Correlation diagram in the COSY (a) and HMQC spectra (b).

The obtained one-dimensional ${ }^{1} \mathrm{H}$ and ${ }^{13} \mathrm{C}$ NMR spectra of the DCOIT sample made it possible to state, unequivocally and reliably, that they correspond to the desired chemical structure according to the literature [16].

\subsection{Analysis of NMR Spectra of SMCS of TPM without Biocide in Chloroform}

The ${ }^{1} \mathrm{H}$ NMR spectrum of the compound is characterized by the presence of three singlet signals at $-0.03,1.59$ and $3.19 \mathrm{ppm}$. The weak singlet signal at $3.19 \mathrm{ppm}$ is probably due to the presence of methoxy groups in the material. The signals at -0.03 and $1.59 \mathrm{ppm}$ are probably due to the presence of methylene and hydroxy-silicon protons (Figure 10).

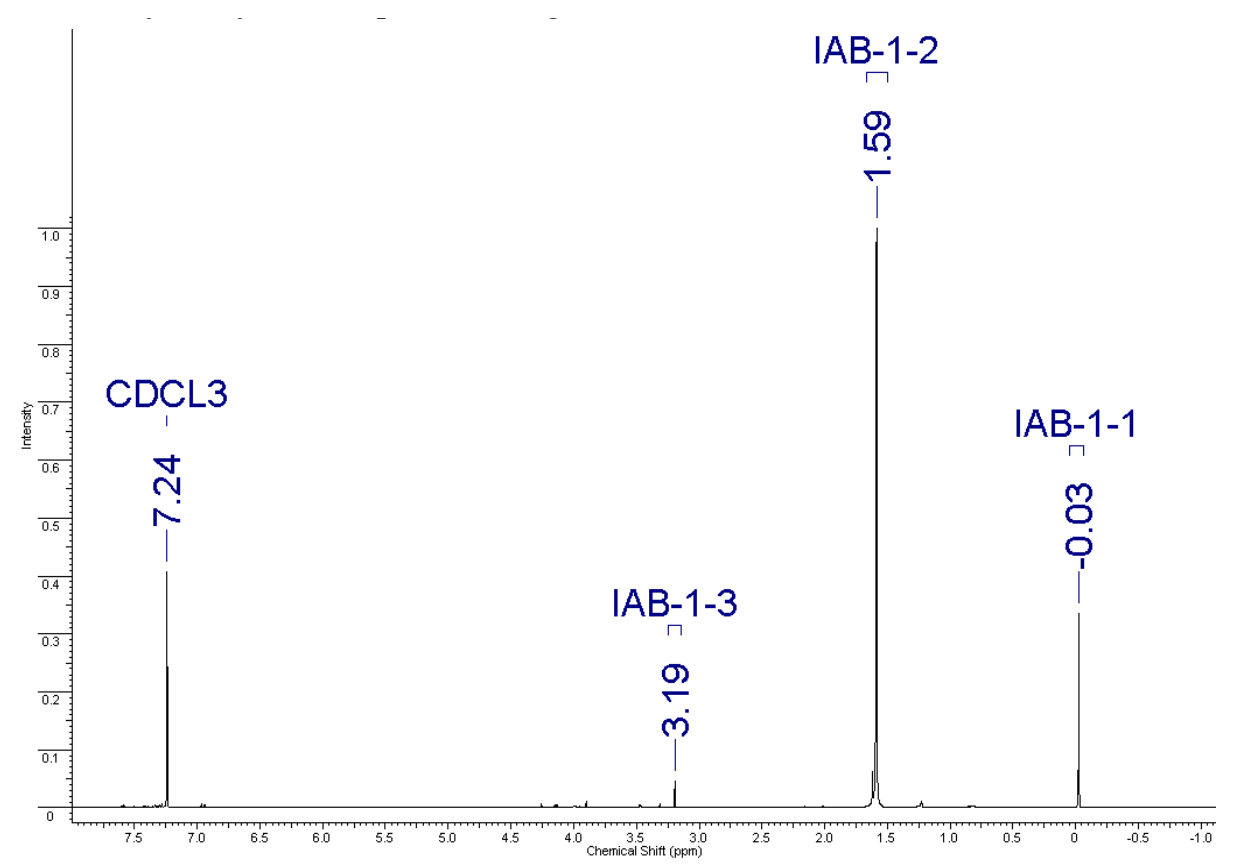

Figure 10. ${ }^{1} \mathrm{H}$ NMR spectra of SMCs without biocide. 


\subsection{Analysis of NMR Spectra of SMCs of TPM with DCOIT}

The NMR spectrum of ${ }^{1} \mathrm{H}$ SMCs TPM containing DCOIT is characterized by the presence of three singlet signals at $-0.03,1.59$ and $3.19 \mathrm{ppm}$. The signals at -0.03 and $1.59 \mathrm{ppm}$ are probably due to the presence of methylene and hydroxy-silicon protons (Figure 11).

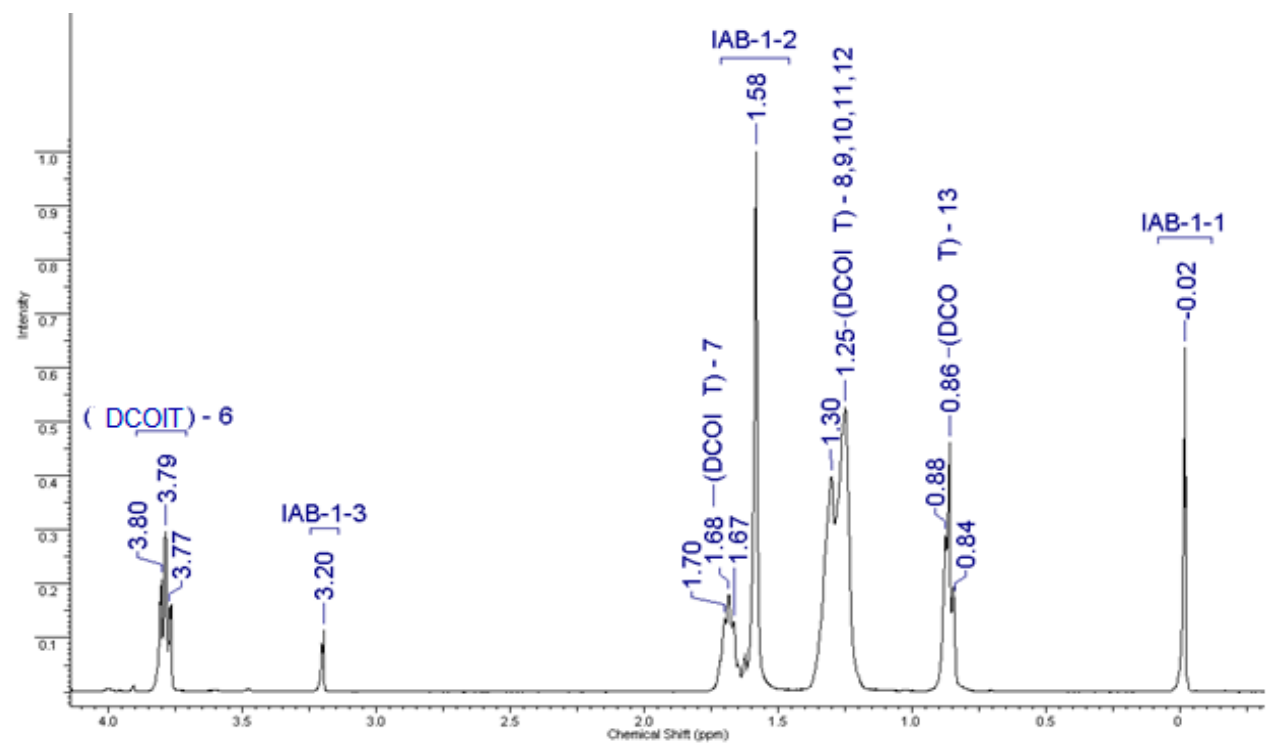

Figure 11. ${ }^{1} \mathrm{H}$ NMR spectra of SMCs with DCOIT.

Tables 1 and 2 show the content of TPM and DCOIT (10\% wt.) in the SMCs.

Table 1. Changes of chemical shifts ${ }^{1} \mathrm{H}$ NMR of TPM in a sample of sub-microcontainers with $10 \%$ DCOIT.

\begin{tabular}{cccc}
\hline \multicolumn{4}{c}{${ }^{\mathbf{1}} \mathbf{H}$ NMR Results, ppm } \\
\hline & $\begin{array}{c}\text { Sample-1 } \\
\text { (SMCs without Biocide) }\end{array}$ & $\begin{array}{c}\text { Sample-2 } \\
\text { (SMCs with 10\% DCOIT) }\end{array}$ & $\boldsymbol{\Delta} \delta=\left(\delta_{\mathbf{0}}-\delta\right)$ \\
\hline Sample-1-1 & -0.03 & -0.02 & $-(-0.01)$ \\
\hline Sample-1-2 & 1.59 & 1.58 & -0.01 \\
\hline Sample-1-3 & 3.19 & 3.20 & 0.01 \\
\hline
\end{tabular}

Table 2. Changes of chemical shifts ${ }^{1} \mathrm{H}$ NMR of DCOIT in the SMC sample with $10 \%$ DCOIT.

\begin{tabular}{cccc}
\hline \multicolumn{4}{c}{${ }^{\mathbf{1}} \mathbf{H}$ NMR Results, $\mathbf{p p m}$} \\
\hline & DCOIT in Chloroform & $\begin{array}{c}\text { Sample-2 } \\
\text { (SMCs with 10\% DCOIT) }\end{array}$ & $\boldsymbol{\Delta} \boldsymbol{\Delta}=\left(\boldsymbol{\delta}_{\mathbf{0}}-\boldsymbol{\delta}\right)$ \\
\hline (DCOIT)-6 & 3.77 & 3.79 & 0.02 \\
\hline (DCOIT)-7 & 1.67 & 1.69 & 0.02 \\
\hline$($ DCOIT)-8,9,10,11,12 & 1.26 & 1.28 & 0.02 \\
\hline (DCOIT)-13 & 0.85 & 0.86 & 0.01 \\
\hline
\end{tabular}

Table 1 shows changes in 1H NMR chemical shifts of TPM samples in the absence of DCOIT and in the presence of $10 \%$ biocide. It has been shown that the presence of DCOIT in the container insignificantly alters the TPM chemical shifts of the shielding supply (Sample-1-1 and Sample-1-3) and de-shielding (Sample-1-2) of TPM protons by the biocide. A slightly larger change in the chemical 
shifts of DCOIT protons is present when they are placed in SMCs (Table 2), and only shielding of biocide protons is present.

The ${ }^{1} \mathrm{H}$ and ${ }^{13} \mathrm{C}$ NMR spectra of the SMCs of TPM with different concentrations of $5 \%, 10 \%, 15 \%$ of DCOIT, as well as the spectra of SMCs of TPM with different concentrations of silicon dioxide were also investigated. In the NMR-spectroscopic picture, different concentrations of biocide and $\mathrm{SiO}_{2}$ did not bring significant changes. The atoms of silicon dioxide in the NMR spectra did not appear, while a change in the concentration of the biocide lead to a proportional increase in the integral intensity of the corresponding signals in the NMR spectrum.

To obtain SMCs, a polycondensation reaction was used, and TPM polymer fragments were fixed on a silicon surface. This will make it difficult for the capsule shell to dissolve when placed in deuterated chloroform. Accordingly, the process of isolating the biocide into the organic solution from the capsule will be difficult. Perhaps an insignificant part of DCOIT will still pass into chloroform as a result of extraction.

The morphology of the outer surface of the SMCs was carried out using a high-resolution scanning electron microscope.

The analysis of the pictures of the SMCs made by scanning electron microscopy shows that the obtained capsules have a spherical shape, the size of which corresponds to the results of the size distribution curves, which show the formation of sub-microcontainers (Figure 12).

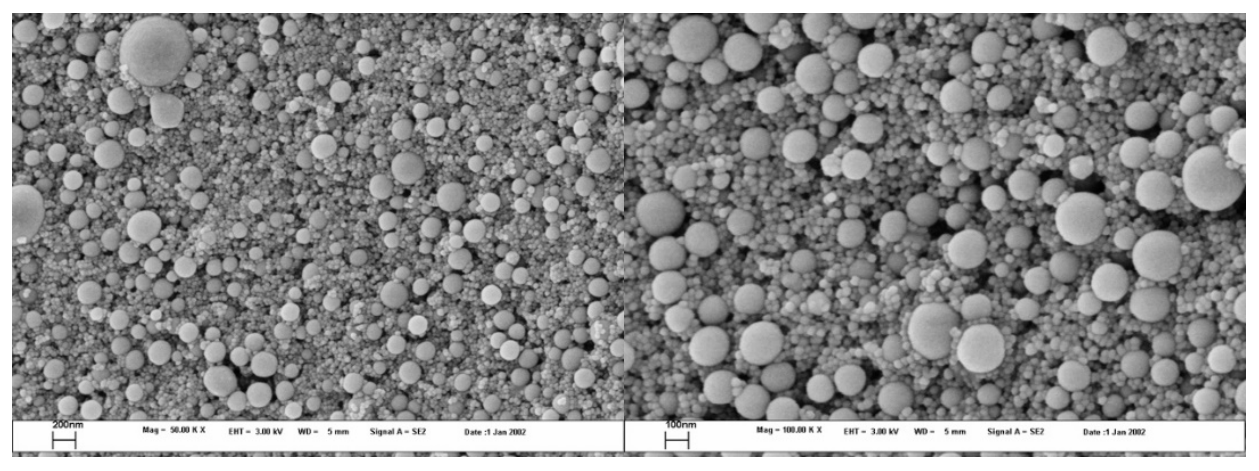

(a) (b)

Figure 12. SEM micrographs of SMCs with DCOIT.

\section{Conclusions}

The creation of polymer coatings containing SMCs with a biocide is necessary, important, and promising for obtaining highly effective submicro-size dispersed materials with an antimicrobial active agent. To achieve the goal of developing SMCs with an antimicrobial agent, complex and systematic studies of the physicochemical properties of both constituent components and emulsions, their colloidal chemical properties in bulk and at various interfaces were carried out.

The SMCs with a shell of silicon dioxide nanoparticles and a core of polymerized 3-(trimethoxysilyl) propyl methacrylate and filled with the biocide DCOIT as an O/W emulsion were obtained. High-resolution magnetic resonance ${ }^{1} \mathrm{H}$ and ${ }^{13} \mathrm{C}$ was used to study the chemical nature of the SMCs. The morphology of the SMCs was determined by scanning electron microscopy and confirmed by measuring their size and zeta-potential by dynamic light scattering.

The results of NMR analysis showed that during the addition of the biocide into the SMCs, the chemical structure of the latter is retained in the containers and it is possible to detect its activity. Minor changes in the chemical shifts of the ${ }^{1} \mathrm{H}$ NMR spectra of the TPM micro- and nano-containers with DCOIT, as well as the biocide itself, confirm the inclusion of the latter in the SMCs. This is due to the intermolecular interaction of protons and carbon atoms of the SMCs of TPM and the DCOIT molecule. A slight change in the chemical shift values of ${ }^{1} \mathrm{H}$ NMR of both SMCs and the DCOIT substrate entering their cavity suggests the relatively weak intermolecular interaction between the 
receptor container and the substrate. It can be noted that the DCOIT alkyl chains are most flexible and undergo the strongest deviation in the process of supramolecular interaction.

Author Contributions: All authors contributed in equal parts to the search and analysis of literature data, writing the text and designing the graphs. Conceptualization, S.B.A. and R.M.; methodology, D.O.G. and T.M.S.; investigation, A.B.I., M.O.I. and A.A.B.; writing-original draft preparation, A.B.I.; writing-review and editing, S.B.A., R.M. and A.A.S. S.B.A. is responsible for the coordination of work and correspondence with the journal. All authors have read and agreed to the published version of the manuscript.

Funding: This research received no external funding.

Acknowledgments: The work was supported by projects №AP05131968, №AP05131984 of the Ministry of Education and Sciences of the Republic of Kazakhstan.

Conflicts of Interest: The authors declare no conflict of interest.

\section{References}

1. Hosseini, M.; Hamdy, M.A. Industrial Applications for Intelligent Polymers and Coatings; Springer International Publishing: Cham, Switzerland, 2016.

2. Sukhorukov, G.B.; Donath, E.; Davis, S.; Lichtenfeld, H.; Caruso, F.; Popov, V.I.; Möhwald, H. Stepwise polyelectrolyte assembly on particle surfaces: A novel approach to colloid design. Polym. Adv. Technol. 1998, 9, 759. [CrossRef]

3. Schneider, G.; Decher, G. From functional core/shell nanoparticles prepared via layer-by-layer deposition to empty nanospheres. Nano Lett. 2004, 4, 1833. [CrossRef]

4. Trojer, M.A.; Li, Y.; Abrahamsson, C.; Mohamed, A.; Eastoe, J.; Holmberg, K.; Nyden, M. Charged microcapsules for controlled release of hydrophobic actives. Part I: Encapsulation methodology and interfacial properties. Soft Matter 2013, 9, 1468. [CrossRef]

5. Given, P.S., Jr. Encapsulation of Flavors in Emulsions for Beverages. Curr. Opin. Colloid Interface Sci. 2009, 14, 43-47. [CrossRef]

6. Ezhilarasi, P.N.; Karthik, P.; Chhanwal, N.; Anandharamakrishnan, C. Nanoencapsulation Techniques for Food Bioactive Components: A Review. Food Bioprocess Technol. 2013, 6, 628-647. [CrossRef]

7. Voigt, A.; Lichtenfeld, H.; Sukhorukov, G.B.; Zastrow, H.; Donath, E.; Bäumler, H.; Möhwald, H. Membrane Filtration for Microencapsulation and Microcapsules Fabrication by Layer-by-Layer Polyelectrolyte Adsorption. Ind. Eng. Chem. Res. 1999, 38, 4037-4043. [CrossRef]

8. Trojer, M.A.; Mohamed, A.; Eastoe, J. A highly hydrophobic anionic surfactant at oil-water, water-polymerand oil-polymer interfaces: Implications for spreading coefficients, polymer interactions and microencapsulation via internal phase separation. Colloids Surf. A Physicochem. Eng. Asp. 2013, 436, 1048-1059. [CrossRef]

9. Tleuova, A.; Mutaliyeva, B.; Aidarova, S.; Schenderlein, M.; Miller, R.; Sharipova, A.; Bekturganova, N.; Grigoriev, D. Selection and study of alkoxylanes as loading in submicrocapsules for self-lubricating coatings. Colloids Surf. A Physicochem. Eng. Asp. 2019, 563, 359-369. [CrossRef]

10. Guardiola, F.A.; Cuesta, A.; Meseguer, J.; Esteban, M.A. Risks of using antifouling biocides in aquaculture. Int. J. Mol. Sci. 2012, 13, 1541-1560. [CrossRef] [PubMed]

11. Jacobson, A.H.; Willingham, G.L. Sea-nine antifoulant: An environmentally acceptable alternative to organotin antifoulants. Sci. Total Environ. 2000, 258, 103-110. [CrossRef]

12. Konstantinou, I.K.; Albanis, T.A. Worldwide occurrence and effects of antifouling paint booster biocide sin the aquatic environment: Are view. Environ. Int. J. 2004, 30, 235-248. [CrossRef]

13. Steen, R.J.C.A.; Ariese, F.; van Hattum, B.; Jacobsen, J.; Jacobson, A. Monitoring and evaluation of the environmental dissipation of the marine antifoulant 4,5-dichloro-2-n-octyl-4-isothiazolin-3-one (DCOIT) in a Danish Harbor. Chemosphere 2004, 57, 513-521. [CrossRef] [PubMed]

14. Moradi, M.; Duan, J.; Du, X. Investigation of the effect of 4,5-dichloro-2-n-octyl-4-isothiazolin-3-one inhibition on the corrosion of carbon steel in Bacillus sp. inoculated artificial seawater. Corros. Sci. 2012, 338-345. [CrossRef]

15. European Union Commission implementing regulation (EU) No. 437/2014 approving 4,5-dichloro-2-octyl-2h-isothiazol-3-one as an existing active substance for use in biocidal products for product-type 21. Off. J. Eur. Union L 2015, 128, 64-67. 
16. Morley, J.O.; Kapur, A.J.O.; Charlton, M.H. Kinetic studies on the reactions of 3-isothiazolones with 2-methyl-2-propanethiol. Int. J. Chem. Kinet. 2007, 39, 254-260. [CrossRef]

17. Arning, J.; Dringen, J.; Schmidt, M.; Thiessen, A.; Stolte, S.; Matzke, M.; Bottin-Weber, U.; Ceasar-Geertz, B.; Jastorff, B.; Ranke, J. Structure-activity relationships for the impact of selected isothiazol-3-one biocides on glutathione metabolism and glutathione reductase of the human liver cell line Hep G2. Toxicology 2008, 246, 203-212. [CrossRef] [PubMed]

18. Zhai, X.; Sun, C.; Li, K.; Agievich, M.; Duan, J.; Hou, B. Composite deposition mechanism of 4,5-dichloro-2-n-octyl-4-isothiazolin-3-one in zinc films for enhanced corrosion resistant properties. J. Ind. Eng. Chem. 2016, 36, 147-153. [CrossRef]

19. Sharipova, A.; Aidarova, S.; Issayeva, A.; Grigoriev, G.; Ibrashev, K.; Gabdullin, M. Synthesis and study of the properties of containers of DCOIT with the polyurea shell. Int. J. Nanotechnol. 2019, 16. [CrossRef]

20. Mal'tseva, E.V.; Ivanov, A.A.; Yudina, N.V. Adsorption Interactions of Humic Acids with Biocides. Russ. J. Phys. Chem. A 2009, 83, 1981-1985. [CrossRef]

21. Brandolini, A.J.; Hills, D.D. NMR Spectra of Polymers and Polymer Additives; Marcel Dekker, Inc.: New York, NY, USA, 2000.

22. Aidarova, S.; Issayeva, A.; Sharipova, A.; Mutaliyeva, B.; Tleuova, A.; Grigoriev, D.; Kudasova, D.; Dzhakasheva, M.; Rysbayeva, G. Synthesis of submicrocontainers with "green" biocide and study of their antimicrobial activity. Colloids Interfaces 2018, 2, 67. [CrossRef]

Publisher's Note: MDPI stays neutral with regard to jurisdictional claims in published maps and institutional affiliations.

(C) 2020 by the authors. Licensee MDPI, Basel, Switzerland. This article is an open access article distributed under the terms and conditions of the Creative Commons Attribution (CC BY) license (http://creativecommons.org/licenses/by/4.0/). 